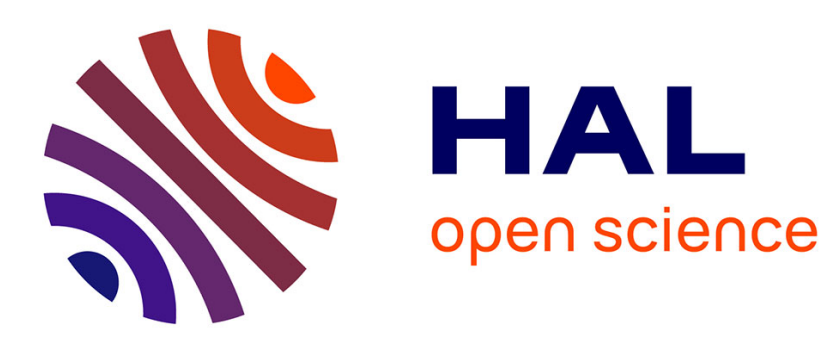

\title{
On the Control of an Exploited Population of Fish
}

\author{
Abderrahman Iggidr, Abderrahim Ouahbi, Jean-Claude Vivalda
}

\section{To cite this version:}

Abderrahman Iggidr, Abderrahim Ouahbi, Jean-Claude Vivalda. On the Control of an Exploited Population of Fish. 1999 European Control Conference (ECC), Aug 1999, Karlsruhe, Germany. 10.23919/ECC.1999.7099447 . hal-01862871

\section{HAL Id: hal-01862871 \\ https://inria.hal.science/hal-01862871}

Submitted on 29 Aug 2018

HAL is a multi-disciplinary open access archive for the deposit and dissemination of scientific research documents, whether they are published or not. The documents may come from teaching and research institutions in France or abroad, or from public or private research centers.
L'archive ouverte pluridisciplinaire HAL, est destinée au dépôt et à la diffusion de documents scientifiques de niveau recherche, publiés ou non, émanant des établissements d'enseignement et de recherche français ou étrangers, des laboratoires publics ou privés. 


\title{
ON THE CONTROL OF AN EXPLOITED POPULATION OF FISH
}

\author{
A. Iggidr ${ }^{b \dagger}$ A. Ouahbi ${ }^{\ddagger} \quad$ J.C. Vivalda ${ }^{b}$ \\ ${ }^{b}$ CONGE Project, INRIA Lorraine \\ \& CNRS UPRES A 7035. Dept. of Mathematics, University of Metz \\ I.S.G.M.P. Bat. A, Ile du Saulcy \\ 57045 Metz cedex 01, FRANCE. \\ e-mail: \{iggidr, vivalda\}@loria.fr fax: +33387547277 \\ ‡Laboratoire d'Automatique et d'Etude des Procédés \\ Faculté des Sciences-Semlalia. Université Cadi Ayyad. B.P S15 \\ Marrakesh. MOROCCO. \\ fax: +2124437409
}

Kcywords : difference equations, Lyapunov functions, population dynamics, stabilization, Feedback.

\section{Abstract \\ The aim of this paper is to show how some tools of control theory can be helpfull to regulate the exploitation of a population of fish.}

\section{Introduction}

In this paper, we are interested in the stabilization of an exploited population of fish arround a non trivial steady state.

The dynamic of the population is supposed to be described by a discrete-time system of the form

$$
x(t+1)=F(x(t), u(t)),
$$

where $x(t)$ is the state variable at time $k=0,1.2 \ldots$ and $u(t)$ is the control (here it is the fishing effort).

The problem addressed here is how to compute the fishing effort (as a feedback control) $u(x)$ in such a way, that for a given state $x^{0} \neq 0$, one has

(i) $F\left(x^{0}: u\left(x^{0}\right)\right)=x^{0}\left(x^{0}\right.$ is an equilibrium point).

(ii) $x^{0}$ is a globally asymptotically stable equilibrium point for the closed-loop system

$$
x(t+1)=F(x(t), u(x(t))) .
$$

\footnotetext{
${ }^{*}$ travail réalisé avec la contribution financière du CNCPRST (Maroc) et du CNRS (France) dans le cadre du PICS $n^{\circ} 78$.

t Corresponding author
}

More precisely. we consider a density-dependent model of a population of exploited fish which is structured in $n$ age classes [liu, mag; ric] :

$$
\left\{\begin{array}{l}
x_{1}(t+1)=f\left(\sum_{i=1}^{n} b_{i} x_{i}(t)\right) \\
x_{2}(t+1)=x_{1}(t) \exp \left(-M_{1}-q_{1} u(t)\right) \\
x_{3}(t+1)=x_{2}(t) \exp \left(-M_{2}-q_{2} u(t)\right) \\
\vdots \\
x_{n}(t+1)=x_{n-1}(t) \exp \left(-M_{n-1}-q_{n-1} u(t)\right)
\end{array}\right.
$$

Where:

- $b_{i} \geq 0$ is the number of individuals produced by individuals of the $i^{\text {th }}$ age class.

- $M_{i} \geq 0$ is the natural mortality of individuals of age $i$.

- $q_{i} \geq 0$ is the catchability of individuals of age $i$.

- $u(t)$ is the fishing effort at time $t$ and is regarded as an input.

- $f$ is the stock-recruitment function. It is a continuous function satisfying $f(0)=0$.

Several authors have proposed different kind of functions $f$ (see [bev, mag. ric]. We shall use in this paper the expression of $f$ used in Beverton and Holt model [bev]

$$
f(x)=\frac{x}{1+\beta x}, \beta>0 .
$$

To construct the stabilizing feedback law: we shall use and adapt a machinery developped in [ben, igg]. 


\section{Main result}

For the sake of simplicity we shall give the result for $n=3$ (the calculus are exactly the same for an arbitrary $n$ but the expression of the feedback is longer). We also suppose that only individuals of age $n$ and over are reproductive $\left(b_{1}=b_{2}=0\right)$. So that, we consider the following system

$$
\left\{\begin{array}{l}
x_{1}(t+1)=f\left(b_{3} x_{3}(t)\right) \\
x_{2}(t+1)=x_{1}(t) \exp \left(-M_{1}-q_{1} u(t)\right) \\
x_{3}(t+1)=x_{2}(t) \exp \left(-M_{2}-q_{2} u(t)\right)
\end{array}\right.
$$

For a constant fishing effort $u^{0}$, system (3) has a non trivial equilibrium state

$$
x_{1}^{0}=\frac{b_{3} a_{1} a_{2}-1}{\beta b_{3} a_{1} a_{2}}=\frac{b_{3} x_{3}^{0}}{1+\beta b_{3} x_{3}^{0}} ; x_{2}^{0}=a_{1} x_{1}^{0} ; x_{3}^{0}=a_{1} a_{2} x_{1}^{0}
$$

Where $a_{i}=\exp \left(-M_{i}-q_{i} u^{0}\right)$.

This steady state belongs to $\Omega=\mathbb{R}_{+}^{3}$ provided that

$$
b_{3}>\frac{1}{a_{1} a_{2}} \text {. }
$$

Theorem 2.1 for any positive constant $\eta \leq u^{0}$, system (3) is globally asymptotically stabilizable by means of the continuous feedback law

$$
u(x)=u^{0}+v(x)
$$

which satisfies

$$
\|v(x)\| \leq \eta, \quad \forall x \in \Omega
$$

Proof. Let $V$ be the following candidate Lyapunov function

$$
V(x)=\left(x_{1}-x_{1}^{0}\right)^{2}+\frac{\left(x_{2}-x_{2}^{0}\right)^{2}}{a_{1}^{2}}+\frac{\left(x_{3}-x_{3}^{0}\right)^{2}}{\left(a_{1} a_{2}\right)^{2}} .
$$

and define

$$
\tilde{\Gamma}(x)=\Gamma\left(x, u^{0}\right)
$$

$\tilde{V}: \Omega \times \mathbb{R} \rightarrow \mathbb{R}$ and

$$
\tilde{V}(x ; u)=V(F(x ; u))
$$

We evaluate the variation of $V$ along the closed-loop system $(3-4)$ :

$$
\begin{aligned}
\Delta V(x)= & V(F(x, u(x)))-V(x) \\
= & \tilde{V}(x, u(x))-V(x) \\
= & \tilde{V}\left(x, u^{0}+v(x)\right)-V(x) \\
= & \tilde{V}\left(x, u^{0}\right)-V(x)+\frac{\partial \tilde{V}}{\partial u}\left(x, u^{0}\right) v(x) \\
& +\int_{0}^{1}(1-t) \frac{\partial^{2} \tilde{V}}{\partial u^{2}}\left(x, u^{0}+t v(x)\right) v^{2}(x) d t .
\end{aligned}
$$

Notice that

$$
\tilde{V}\left(x, u^{0}\right)=V\left(F\left(x, u^{0}\right)\right)
$$

and

$$
\frac{\partial \hat{V}}{\partial u}\left(x, u^{0}\right)=\frac{\partial V}{\partial x}\left(\Gamma\left(x, u^{0}\right)\right) \frac{\partial F}{\partial u}\left(x, u^{0}\right)
$$

So.

$$
\begin{aligned}
\Delta V(x)= & V\left(F\left(x, u^{0}\right)\right)-V(x) \\
& +\frac{\partial V}{\partial x}\left(F\left(x, u^{0}\right)\right) \frac{\partial F}{\partial u}\left(x: u^{0}\right) v(x) \\
& +\int_{0}^{1}(1-t) \frac{\hat{\sigma}^{2} \hat{V}}{\partial u^{2}}\left(x, u^{0}+t v(x)\right) v^{2}(x) d t .
\end{aligned}
$$

Now we shall construct a feedback control $v(x)$ in order to get $\Delta V(x) \leq 0$ for all $x \in \Omega$. To this end, we introduce some notations. Let $\varphi: \Omega \times \mathbb{R} \times \mathbb{R} \rightarrow \mathbb{R}$ be the function defined by

$\varphi(x, v, u)=\int_{0}^{1}(1-t) v^{T}(x) \frac{\partial^{2} \tilde{V}}{\partial u^{2}}\left(x, u^{0}+t v(x)\right) w^{2}(x) d t$

For a fixed number $\eta$ satisfying $0<\eta<u^{0}$ : let $K_{1}(x)$ and $K_{2}(x)$ be any nonnegative continuous real valued functions satisfying $K_{1}(x)+K_{2}(x) \neq 0, \quad \forall x \in \Omega$ and

$$
\begin{aligned}
& K_{1}(x) \geq \sup _{|v| \leq \eta,|u|=1}|\varphi(x, u, w)|, \quad \forall x \in \Omega . \\
& K_{2}(x) \geq\left|\frac{\partial V}{\partial x}\left(F\left(x, u^{0}\right)\right) \frac{\partial f}{\partial u}\left(x, u^{0}\right)\right|, \quad \forall x \in \Omega .(11
\end{aligned}
$$

and set

$$
K(x)=\frac{\eta}{\eta K_{1}(x)+K_{2}(x)}>0 \forall x \in \Omega
$$

We construct the feedback control according to the following formula :

$$
v(x)=-K(x)\left(\frac{\partial V}{\partial x}\left(F\left(x, u^{0}\right)\right) \frac{\partial F}{\partial u}\left(x, u^{0}\right)\right)
$$

which satisfies

$$
|v(x)| \leq \eta: \quad \forall x \in \Omega
$$

Tacking into account (8-13-9), the variation of $V$ along the solutions of the closed-loop system can be written :

$$
\begin{aligned}
\Delta V(x)= & V\left(F\left(x, u^{0}\right)\right)-V(x) \\
& -\frac{1}{K(x)} v^{2}(x)+\varphi(x, v(x), v(x)) .
\end{aligned}
$$

On the one hand, we have

$$
\begin{aligned}
& V\left(F\left(x, u^{0}\right)\right)-V(x)=\left(f\left(b_{3} x_{3}\right)-x_{1}^{0}\right)^{2}-\frac{\left(x_{3}-x_{3}^{0}\right)^{2}}{\left(a_{1} a_{2}\right)^{2}} \\
& =\left(\frac{b_{3} x_{3}}{1+\beta b_{3} x_{3}}-x_{1}^{0}\right)^{2}-\left(\frac{x_{3}-x_{3}^{0}}{a_{1} a_{2}}\right)^{2} \\
& =\left(\frac{b_{3} x_{3}}{1+\beta b_{3} x_{3}}-\frac{b_{3} x_{3}^{0}}{1+\beta b_{3} x_{3}^{0}}\right)^{2}-\left(\frac{x_{3}-x_{3}^{0}}{a_{1} a_{2}}\right)^{2}
\end{aligned}
$$


Hence

$$
\begin{aligned}
& V\left(F\left(x, u^{0}\right)\right)-V(x)= \\
& \left(\frac{b_{3}\left(x_{3}-x_{3}^{0}\right)}{\left(1+\beta b_{3} x_{3}\right)\left(1+\beta b_{3} x_{3}^{0}\right)}\right)^{2}-\left(\frac{x_{3}-x_{3}^{0}}{a_{1} a_{2}}\right)^{2} \\
& =\frac{\left(b_{3} a_{1} a_{2}\right)^{2}-\left(1+\beta b_{3} x_{3}\right)^{2}\left(1+\beta b_{3} x_{3}^{0}\right)^{2}}{\left(a_{1} a_{2}\right)^{2}\left(1+\beta b_{3} x_{3}\right)^{2}\left(1+\beta b_{3} x_{3}^{0}\right)^{2}}\left(x_{3}-x_{3}^{0}\right)^{2}
\end{aligned}
$$

We have $1+\beta b_{3} x_{3}^{0}=1+\beta b_{3} \frac{b_{3} a_{1} a_{2}-1}{\beta b_{3} a_{1} a_{2}} a_{1} a_{2}=b_{3} a_{1} a_{2}$. This yields.

$$
\begin{gathered}
V\left(F\left(x_{2}, u^{0}\right)\right)-V(x)= \\
\frac{1-\left(1+\beta b_{3} x_{3}\right)^{2}}{\left(1+\beta b_{3} x_{3}\right)^{2}\left(1+\beta b_{3} x_{3}^{0}\right)^{2}} b_{3}^{2}\left(x_{3}-x_{3}^{0}\right)^{2} \leq 0
\end{gathered}
$$

On the other hand, $\varphi(x, v, w)$ being homogeneous of degree 2 with respect to $u$; we have for all $x \in \Omega$ such that $v(x) \neq 0$ :

$$
\varphi(x, v(x), v(x))=v^{2}(x) \varphi\left(x, v(x), \frac{v(x)}{|v(x)|}\right)
$$

From this and (15-16), we get

$$
\Delta V(x)=V\left(F\left(x, u^{0}\right)\right)-V(x) \leq 0 \text { if } v(x)=0 .
$$

And for $v(x) \neq 0$;

$$
\begin{aligned}
\Delta V(x)= & V\left(F\left(x, u^{0}\right)\right)-V(x) \\
& -v^{2}(x)\left(\frac{1}{K(x)}-\varphi\left(x ; v(x) ; \frac{v(x)}{\mid v(x)}\right)\right) .
\end{aligned}
$$

Thanks to the construction of $v(x)$ and $K(x)$; we have $\frac{1}{K(x)}>\varphi\left(x, v(x), \frac{v(x)}{|v(x)|}\right)$. This allows to conclude that

$$
\Delta V(x) \leq 0 \quad \forall x \in \Omega .
$$

The closed-loop system is then Lyapunov stable. On the other hand.

$$
\Delta V(x)=0 \Leftrightarrow x_{3}=x_{3}^{0} \text { and } v(x)=0 .
$$

It is easy to show that the largest invariant set contained in

$$
\{x \in \Omega \mid \Delta V(x)=V(F(x, u(x)))-V(x)=0\}
$$

is reduced to $\left\{x^{0}\right\}$ so, by Lasalle Invariance Principle [las]; the equilibrium $x^{0}$ is a globally asymptotically stable equilibrium point for the closed-loop system.

\section{References}

[ben] M. Bensoubaya, A. Ferfera and A. Iggidr. Stabilisation de systèmes non linéaires discrets Comptes Rendus de l'Académie des Sciences Paris, Série I, t.321. pp 371-374, (1995). [bev] R.J.H. Beverton and S.J. Holt. On the dynamics of exploited fish populations. Chapman \& Hall, New York. First edition 1957.

[fis] M. E. Fisher and B. S. Goh. Stability results for delayed-recuitment models in population dynamics. J. Math. Bio., 19, 147-156, (1984).

[igg] A. Iggidr and M. Bensoubaya. New results on the stability of discrete-time systems and applications to control problems. Journal of Mathematical Analysis and Applications, 219, 392-414. (1998).

[las] J.P. LASALLE. The stability and control of discret processes. Springer-Verlag, New York, 1986.

[liu] L. Liu and J. E. Cohen. Equilibrium and local stability in a logistic matrix model for age-structured populations. J. Math. Bio., 25, 73-88, (1987).

[mag] P. Magal and D. Pelletier A fixed point theorem with application to a model of population dynamics. J. Difference Equ. Appl., 3. No.1, 65-87. (1997).

[ric] W. E. Ricker. Stock and recruitment. J. Fish. Res. Board Can., 11, 559-623, (1954). 